\title{
MICROORGANISM VARIABILITY OF THE SOIL AND THE INHIBITION OF THE BANANA FUSARIUM WILT BY STRAW ADDITION COMBINED WITH FLOODING
}

\author{
FAN, P. ${ }^{\#}$ - CHENG, J. ${ }^{\#}-$ RUAN, Y. ${ }^{*}$ \\ Hainan Key Laboratory for Sustainable Utilization of Tropical Bio-resources, College of \\ Tropical Crops, Hainan University, Haikou 570228, PR China \\ ${ }^{\#}$ These authors contributed equally to this work \\ *Corresponding author \\ e-mail: ruanyunze1974@hainanu.edu.cn \\ (Received $18^{\text {th }}$ Nov 2020; accepted $27^{\text {th }}$ Jan 2021)
}

\begin{abstract}
Straw addition combined with flooding is a form of the Reductive Soil Disinfestation (RSD) which can effectively prevent soil-borne diseases to some extent. However, little is known about the continuous effects of straw addition combined with flooding on the key culturable microbes and the pathogen Fusarium oxysporum in soils susceptible to banana Fusarium wilt (BFW). We studied the effects of continuous cropping (CK), fallow (FW), flooding (RSD-FD) and straw addition combined with flooding (RSD-FS) treatments for 0-120 days on soil properties and the dominant culturable microorganisms. Compared to CK, RSD-FS treatment had the lowest incidence of BFW; RSDFS treatments significantly increased soil $\mathrm{pH}$, but soil Eh and the number of Fusarium Oxysporum, culturable bacteria and fungi decreased significantly after flooding (30 days). The bacteria genera Agrobacterium, Enterobacter, Aeromonas, and the fungal genera Trichoderma, Penicillium and Myxoflagella increased with the time of flooding; while the bacteria genera Pseudoxanthomonas, Sphingomonas and Leckercia, decreased first and then increased; Interestingly, the bacterial genera Bacillus and Brevibacterium, and the fungal genera Phoma, Coprinus and Filamentous could not be cultured after flooding (30 days). Therefore, RSD-FS treatment could change the microbial flora and increase the general inhibition of the highly susceptible banana soil.
\end{abstract}

Keywords: Fusarium oxysporum, reductive soil disinfestation, species composition, Leckercia, Trichoderma

\section{Introduction}

Bananas (Musa nana Lour) are the main source of food and income for many people in the tropics and subtropics (FAOSTAT, 2017). Today nearly 50\% of the world's banana production is made up of the Cavendish (Musa Aaa) variety, which is susceptible to the current widespread pathogenic strain of Fusarium oxysporum $f$. sp. tropical Race 4 (Foc TR4), which causes banana fusarium wilt that is threatening banana production worldwide (Mostert et al., 2017). There is no commercially effective way to control Foc TR4 (Ploetz, 2015). Even though some Foc TR4 resistant varieties such as Goldfinger and Taiwanese GCTCV somaclones (Hwang and Ko, 2004) have also been produced, their yields are nowhere near as high as that of the Cavendish variety, so continued large-scale production of bananas depends on agronomic management of the fusarium wilt disease.

Reductive Soil Disinfestation (RSD) was an effective method to suppress various types of soil-borne diseases in various crops (Messiha et al., 2007), that was interpreted to add a lot of easily decomposed organic materials, irrigation, film mulching or flooding to block gas exchange with the atmosphere, quickly creating strong reduction 
environment of soil, killing soil-borne pathogens in a short period of time (Liu et al., 2019; Larkin and Griffin, 2007). Crop straw is rich in organic carbon and essential nutrient elements, which can promote soil organic matter accumulation, improve soil physical and chemical properties and increase soil fertility (Franzluebbers, 2002; Rasool et al., 2008; Surekha et al., 2003), which could make up for the shortcomings that flooding tends to promote soil erosion and degradation (Alkhaibari et al., 2018). It was also observed that the anaerobic soil formed by straw addition combined with flooding could drive microbial factors, improve soil microbial community and inactivate pathogens, thus inhibit the growth of $F$. oxysporum and prevent the occurrence of banana wilt (Wen et al., 2016). Previous studies have reported that combined flooding with $2 \%(\mathrm{w} / \mathrm{w})$ maize (Zea mays) straw could significantly decrease the population of $F$. oxysporum and the relative abundances of fungi such as Chaetomium spp. and Penicillium spp, but significantly increased $\mathrm{pH}$ and the relative abundances of bacteria belonging to the phylum Bacteroidetes, Acidobacteria and Planctomycetes, which that was beneficial to the disease suppression (Huang et al., 2015). Recent reports also studied the RSD effecting on cucumber damping-off diseased, and the result showed that the potential benefit species which were negatively correlated with disease incidence and positively associated with the change of the soil environment, such as bacterial order Sphingobacteriales and fungal order Sordariales was significantly increased and led to the soil more disease-suppressive and beneficial to the soil nutrient cycling and banana growth (Liu et al., 2019).

key microorganism's dynamic in a disease-suppressed banana soil and their potential relation to the soil-borne pathogens and soil environments during and after the straw addition combined with flooding remains are poorly understood. Therefore, we conducted a greenhouse pot experiment to identify the dynamic changes of the abundance of cultivable pathogen $F$. oxysporum and the dominant cultivable bacteria and fungus and microbial community, and their relationship with the RSD-soil properties from 0 to 120 days by straw addition combined with flooding to provide the theoretical guidance for the controlling of banana fusarium wilt.

\section{Materials and Methods}

\section{Experimental design and soil}

The soil was come from the banana fields which have continuously cropped for seven years, and the incidence of banana fusarium wilt was $50 \%$ higher. The basic properties of the soil were as follows: organic matter $10.98 \mathrm{~g} \cdot \mathrm{kg}^{-1}$, alkali-hydrolyzed nitrogen $23.71 \mathrm{mg} \cdot \mathrm{kg}^{-1}$, available phosphorus $102.55 \mathrm{mg} \cdot \mathrm{kg}^{-1}$, available potassium $237.15 \mathrm{mg} \cdot \mathrm{kg}^{-1}, \mathrm{pH} 6.5, F$. oxysporum count $2 \times 104 \mathrm{CFU} \cdot \mathrm{kg}^{-1}$. The greenhouse culture experiment was conducted from June 1, 2019, to December 27, 2019, in Ledong County, Hainan Province, China. The location was $18^{\circ} 42^{\prime} \mathrm{N}, 108^{\circ} 48^{\prime} \mathrm{E}$. The experiment consisted of four treatments: continuous cropping $(\mathrm{CK})$, fallow (FW), flooding (RSD-FS), straw addition combined with flooding (RSD-FS), 10 repetitions per treatments, and $5.5 \mathrm{~kg}$ of $2 \mathrm{~mm}$ sieved soil in each pot which is $23.5 \mathrm{~cm}$ diameter and $20 \mathrm{~cm}$ height, $110 \mathrm{~g}$ rice straw which crushed by micro-pulverize, after the rice straw and the soil were mixed and homogenized, the soil in the basin was kept smooth and filled with water until the soil was saturated. The test period was 120 days, and 30 days was the interval. The soil samples were collected 4 times, and the submergence depth of each treatment was $3 \mathrm{~cm}$. After flooding, the next generation 
banana was planted after the flooding over, and the incidence of banana fusarium wilt was calculated after 3 months. Before planting the next banana, $55 \mathrm{~g}$ bio-organic fertilizer was followed in each pot. The bio-organic fertilizer was acquired from Jiangsu Huarun Earth Fertilizer Co., Ltd. The banana variety is 'Brazil', which was provided by the experimental research base of Heat Science Academy of Danzhou Campus of Hainan University. Rice (Nanjing 2728 Yinnuo) Straw was taken in 2018 at the local rice fields.

\section{Soil collection and properties}

After removing the dead branches and leaves from the soil surface layer, 10 soil columns with a depth of $5-10 \mathrm{~cm}$ and a diameter of $2 \mathrm{~cm}$ were randomly collected with a soil drill, with the center of the pot plant circle as the center, mix the remaining soil into a sample. After homogenizing the soil samples, the samples were divided into three parts. One part of the soil was air-dried naturally, then the soil was sieved through $2 \mathrm{~mm}$ sieve to determine the physical and chemical properties of the soil, one part of the soil was stored in a $4{ }^{\circ} \mathrm{C}$ refrigerator for picking up single strains of soil. Soil $\mathrm{pH}$ and $\mathrm{Eh}$ was determined using a soil-to-water ratio of 1:2.5 (w/v). The exchangeable ammonia $\left(\mathrm{NH}_{4}{ }^{+}-\mathrm{N}\right)$ and nitrate $\left(\mathrm{NO}_{3}{ }^{-}-\mathrm{N}\right)$ in the soil was extracted with $2 \mathrm{M} \mathrm{KCl}(\mathrm{w} / \mathrm{v}, 1: 5)$ and determined on a Continuous flow analyzer (Foss Tecator, Hillerød, Denmark).

\section{Determination of the number of culturable microorganisms in soil}

The number of F. oxysporum, bacteria, fungi and actinomycetes in the soil was determined by the plate dilution coating method (Ben-David and Davidson, 2014). The culturable F. oxysporum were counted using the improved Komada 2 medium at $28{ }^{\circ} \mathrm{C}$ for $96 \mathrm{~h}$ (Komada, 1975). The bacteria were cultured in Luria-Bertani (LB) medium at $30{ }^{\circ} \mathrm{C}$ for $24 \mathrm{~h}$ (Macwilliams and Liao, 2006), and the fungi were cultured in Martin medium at $28{ }^{\circ} \mathrm{C}$ for $72 \mathrm{~h}$ (Martin, 1981), the number expressed as colony forming unit (CFU) per gram of dry soil.

\section{Isolation and identification of culturable bacteria and fungi}

Isolation of single bacterial strain from microbial community using LB medium. Martin medium is used to isolate individual fungal strains from the microbial community. According to the manufacturer's instructions, single-strain DNA is extracted from the purified culture using a bacterial Genomic DNA Extraction Kit (DP302) (Tiangen biotech (Beijing) Co., Ltd.) and Fungi Genomic DNA Extraction Kit Fungal genomic (D2300) (Beijing Suolaibao Technology Co., Ltd.). The primer pair 27F(5'-AGAGTTT-GATCCTGGCTCAG-3') and 1492R(5'GGTTACCTTGTTACGACTT-3') was selected to amplify the 16S rRNA gene (Yu et al., 2013). The primer pair ITS1(5'-TCCGTAGGTGAACCTGCGG-3') and ITS4(5'TCCTCCGCTTATTGATATGC-3') were used for the fungal ITS1 gene (Schoch et al., 2012) 18. We established a $50-\mu 1$ of reaction solution including $25 \mu \mathrm{l}$ of TaKaRa Ex Taq ${ }^{\circledR}$ Premix (Takara Bio Inc., Japen), $0.5 \mu$ of each primer $(10 \mu \mathrm{M}), 4 \mu \mathrm{l}$ of template DNA, and $20 \mu \mathrm{l}$ of sterile water. Cycling conditions were as follows: $95{ }^{\circ} \mathrm{C}$ for $10 \mathrm{~min}$ polymerase activation, followed by 45 cycles of denaturation at $95{ }^{\circ} \mathrm{C}$ for $30 \mathrm{~s}$, annealing at $55^{\circ} \mathrm{C}$ (bacteria) and $50{ }^{\circ} \mathrm{C}$ (fungi) for $45 \mathrm{~s}$, and extension at $72{ }^{\circ} \mathrm{C}$ for $60 \mathrm{~s}$ used the Bio-Rad Bole PCR T100. The purified PCR product was analyzed with the Illumina MiSeq platform at Personal Biotechnology Co., Ltd. (Shanghai, China). 
Taxonomy assignment was performed using BLASTP (Version 2.2.28+, http://blast.ncbi.nlm.nih.gov/Blast.cgi) by aligning non-redundant gene catalogs against NCBI database (Altschul et al., 1997).

\section{Statistical analysis}

The test data was processed and plotted with Microsoft Excel 2016. Variance analysis and Pearson correlation analysis were carried out with SPSS 20.0 (IBM Corporation, USA). Multiple comparisons were conducted with Least-significantdifference (LSD) at a $\mathrm{p}=0.05$ level.

\section{Results}

\section{Soil properties and Fusarium wilt disease influenced by straw addition combined with flooding}

RSD-FS treatment (straw addition combined with flooding) significantly affected soil Eh, ammonium and nitrate contents $(\mathrm{p}<0.01)$ (Table Al). Compared with CK treatment and FW treatment, soil Eh and ammonium in soil treated with RSD-FD and RSD-FS significantly decreased after the 30th day of flooding, while the soil nitrate and $\mathrm{pH}$ significantly increased, after that, the trend gradually eased with the extension of flooding time ( $\mathrm{p}<0.05)$ (Fig. 1). Pearson correlation showed that flooding duration was positively correlated with soil $\mathrm{pH}$ and ammonium content, but negatively correlated with Eh and nitrate nitrogen content by the RSD-FS treatment $(\mathrm{p}<0.01)($ Table 1).
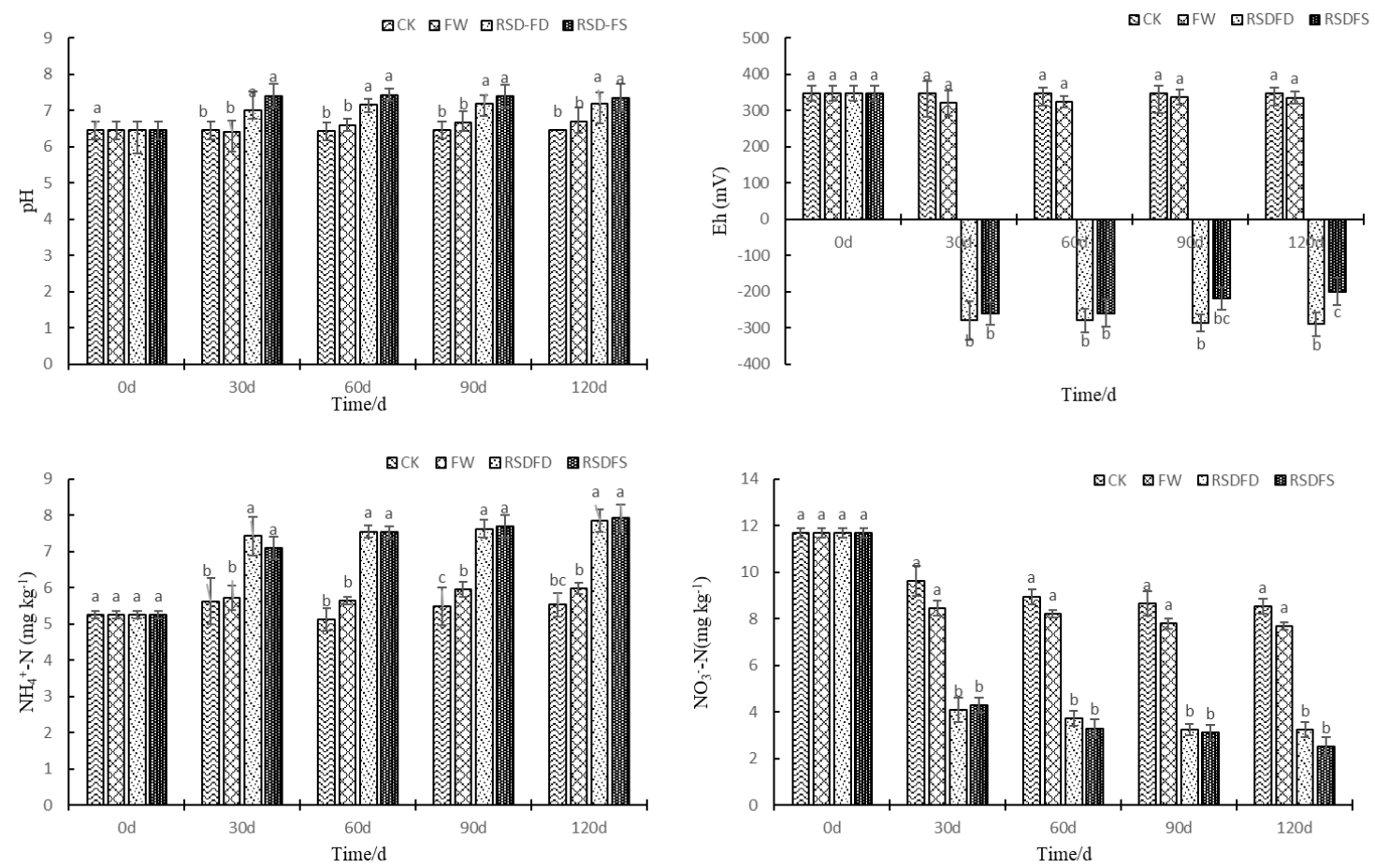

Figure 1. Effects of straw addition combined with flooding on soil Eh, $\mathrm{pH}$, ammonium and nitrate contents. CK: continuous cropping; FW: Fallow; RSD-FD: Flooding; RSD-FS:

Flooding + Straw. Error bars indicate standard error $(n=3)$. Different small letters indicate a significant difference among treatments at the 0.05 level 
In addition, $\mathrm{CK}$ treatment has the highest incidence of banana fusarium wilt (BFW), and followed by FW treatment (Fig. 2). Compared with $\mathrm{CK}$ and FW treatments the incidence of BFW with RSD-FS and RSD-FD was significantly lower ( $\mathrm{p}<0.05), 50 \%$ and $37.5 \%$ lower than CK, respectively.

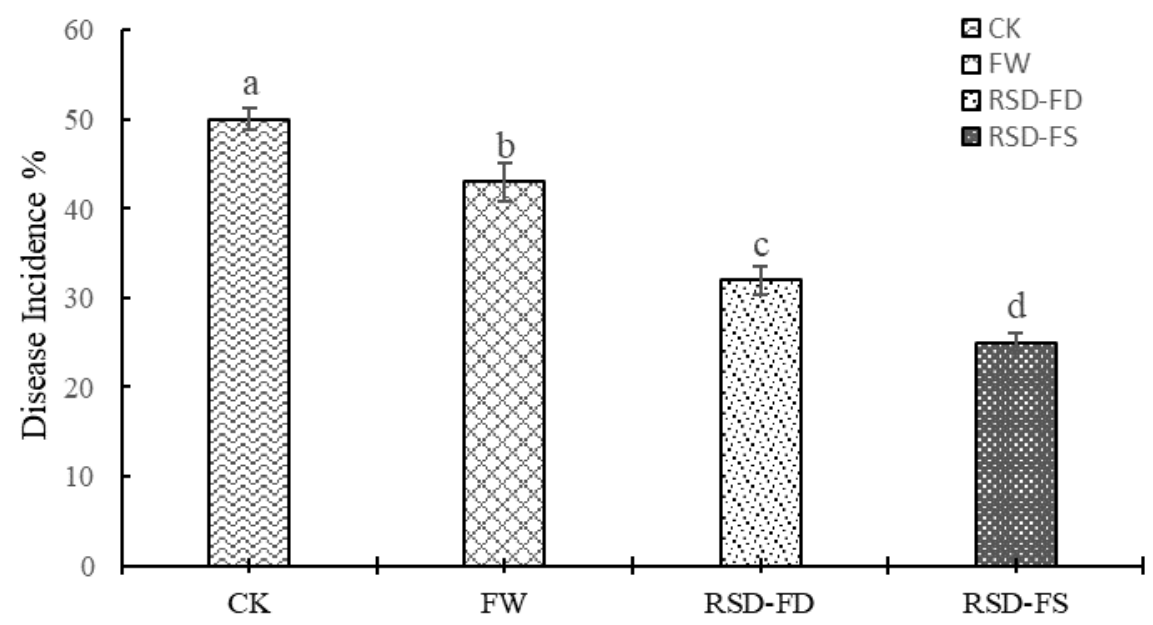

Figure 2. Incidence of banana Fusarium wilt of the next generation banana after flooding. CK: continuous cropping; FW: Fallow; RSD-FD: Flooding; RSD-FS: Flooding + Straw. Error bars indicate standard error $(n=3)$. Different small letters indicate a significant difference among treatments at the 0.05 level

\section{The number of culturable microorganisms under straw addition combined with flooding}

Both fallow and flooding could significantly reduce the number of soil $F$. oxysporum. Moreover, the number of soil F. oxysporum flooding treatments (RSD-FD and RSD-FS) was significantly lower than fallow treatments and became stable after (90 days) ( $p<0.05)$. However, both of RSD-FD and RSD-FS treatments was significantly lower after the 30th day than other treatments and lasted until the 120th day. On the 90th day, FW, RSD-FD, and RSD-FS treatments significantly decreased than CK treatment $18.33 \%, 60 \%$ and $62.25 \%(\mathrm{p}<0.05)$, respectively. RSD-FS treatment significantly decreased to $4.2 \times 10^{3} \mathrm{CFU} \mathrm{g}^{-1}$ (dry soil). The results of variance analysis showed that straw addition combined with flooding significantly affected the number of $F$. oxysporum $(\mathrm{F}=3238.1, \mathrm{p}<0.01)$ (Table A1), and the Pearson correlation analysis showed that the number of $F$. oxysporum decreased with the increase of flooding time $(\mathrm{p}<0.01)$ (Table 1).

Compared with CK treatment, the number of culturable bacteria after 60 days was significantly lower under other treatments $($ Fig. $3 b)(\mathrm{p}<0.05)$, and all treatments tended to stabilize to the120th day. In general, the number of bacteria in soil under RSD-FS treatment was the lowest, followed by RSD-FD and FW treatment.

There was no significant change in the number of culturable fungi in $\mathrm{CK}$ and FW treatments. Compared with CK and FW treatment, the number of culturable fungi in the soil under flooding treatment (RSD-FS and RSD-FS) after the 30th day was significantly reduced, while the number of culturable fungi was the lowest after flooding to the 60th day, the culturable fungi in RSD-FD and RSD-FS treatments were $46.84 \%$ and $17.72 \%$ of the control, respectively, and tended to stabilize to120th day $($ Fig. 3c) $(\mathrm{p}<0.05)$. The results of 
variance analysis showed that Straw addition combined with flooding significantly affected the number of culturable bacteria $(\mathrm{F}=351.49, \mathrm{p}<0.01)$ and the number of culturable fungi $(\mathrm{F}=244.72, \mathrm{p}<0.01)$ (Table A1), and the correlation analysis shows that both of them decrease with the increase of flooding time (Table 1$)(\mathrm{p}<0.05)$.

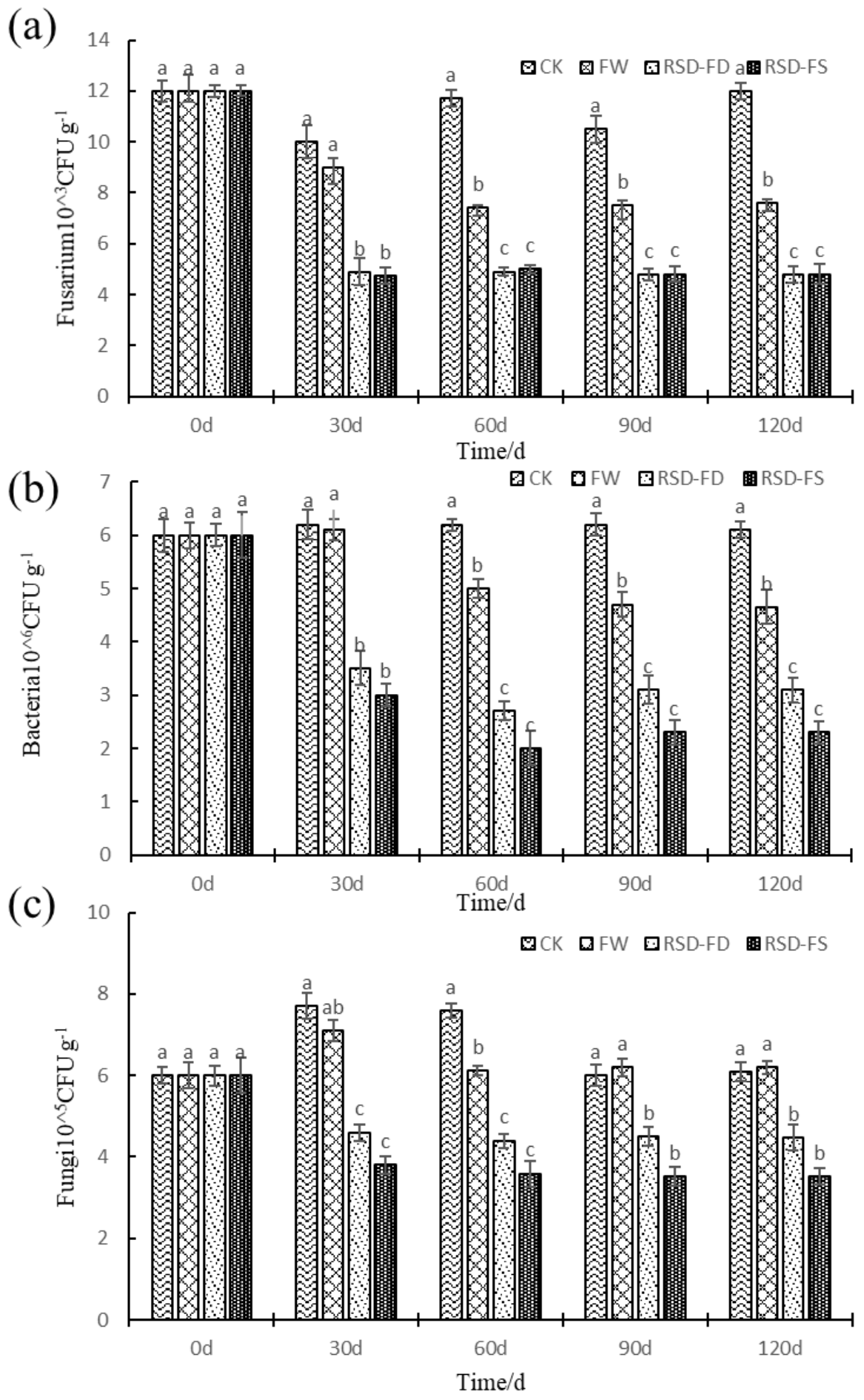

Figure 3. Effects of straw addition combined with flooding on the number of $F$. oxysporum (a), bacteria (b) and fungi (c). CK: continuous cropping; FW: Fallow; RSD-FD: Flooding; RSD-

FS: Flooding + Straw. Error bars indicate standard error $(n=3)$. Different small letters indicate a significant difference among treatments at the 0.05 level. CFU, colony forming unit 
Table 1. Pearson correlation analysis of investigation parameters

\begin{tabular}{|c|c|c|c|c|c|c|}
\hline & Time & pH & Eh & $\mathrm{NH}_{4}{ }^{+}-\mathrm{N}$ & $\mathrm{NO}_{3}-\mathrm{N}$ & F. oxysporum CFU \\
\hline Time & - & $0.68 * *$ & -0.59 & $0.87 * *$ & $-0.81 * *$ & $-0.71 * *$ \\
\hline F. oxysporum CFU & $-0.71 * *$ & $-0.99 * *$ & $0.87 * *$ & $-0.96 * *$ & $0.98 * *$ & - \\
\hline Bacteria CFU & $-0.78 * *$ & $-0.97 * *$ & $0.79 * *$ & $-0.98 * *$ & $0.99 * *$ & $0.97 * *$ \\
\hline Fungus CFU & $-0.74 * *$ & $-0.99 * *$ & $0.84 * *$ & $-0.97 * *$ & $0.99 * *$ & $0.99 * *$ \\
\hline \multicolumn{7}{|l|}{ Bacterial genera } \\
\hline Bacillus & $-0.71 * *$ & $-0.99 * *$ & $0.86 * *$ & $-0.96 * *$ & $0.99 * *$ & $1.00 * *$ \\
\hline Lysine Bacillus & $-0.89 * *$ & - & - & - & $0.57^{*}$ & 0.48 \\
\hline Pseudoxanthomonas & $0.69 * *$ & - & - & - & - & 0.01 \\
\hline Oligomonas & $-0.95^{* *}$ & $-0.83 * *$ & $0.67 * *$ & $-0.96 * *$ & $0.92 * *$ & $0.84 * *$ \\
\hline Sphingomonas & $0.61 * *$ & - & - & - & - & - \\
\hline Agrobacterium & - & - & - & - & - & - \\
\hline Leckercia & $0.84 * *$ & - & - & - & - & - \\
\hline Enterobacter & 0.38 & $0.92 * *$ & $-0.80 * *$ & $0.78 * *$ & $-0.85 * *$ & $-0.92 * *$ \\
\hline Aeromonas & $-0.75 * *$ & -0.16 & - & - & $0.34 * *$ & $0.17 * *$ \\
\hline Brevibacterium & $-0.71 * *$ & $-0.99 * *$ & $0.86^{* *}$ & $-0.96 * *$ & $0.99 * *$ & $1.00 * *$ \\
\hline \multicolumn{7}{|l|}{ Fungal genus } \\
\hline Aspegillus & $-0.99 * *$ & $-0.72 * *$ & 0.61 & $-0.89 * *$ & $0.84 * *$ & $0.74 * *$ \\
\hline Trichoderma & $0.81 * *$ & $0.97 * *$ & $-0.86^{* *}$ & $0.99 * *$ & $-1.00 * *$ & $-0.99 * *$ \\
\hline Penicillium & $0.98 * *$ & $0.79 * *$ & $-0.65^{* *}$ & $0.93 * *$ & $-0.89 * *$ & $-0.80 * *$ \\
\hline Penicillium & $0.89 * *$ & $0.94 * *$ & $-0.80 * *$ & $1.00 * *$ & $-0.99 * *$ & $-0.95 * *$ \\
\hline Fusarium & $-0.78 * *$ & $-0.97 * *$ & $0.85 * *$ & $-0.98 * *$ & $0.99 * *$ & $0.99 * *$ \\
\hline Myxoflagella & $0.97 * *$ & $0.82 * *$ & $-0.67 * *$ & $0.95 * *$ & $-0.91 * *$ & $-0.83 * *$ \\
\hline Trametes & $0.97 * *$ & $0.68 * *$ & $-0.52 *$ & $0.86^{* *}$ & $-0.80 * *$ & $-0.68 * *$ \\
\hline Phoma & $-0.71 * *$ & $-0.99 * *$ & $0.86 * *$ & $-0.96 * *$ & $0.99 * *$ & $1.00 * *$ \\
\hline Coprinus & $-0.71 * *$ & $-0.99 * *$ & $0.86^{* *}$ & $-0.96^{* *}$ & $0.99 * *$ & $1.00 * *$ \\
\hline Filamentous & $-0.71 * *$ & $-0.99 * *$ & $0.86^{* *}$ & $-0.96 * *$ & $0.99 * *$ & $1.00 * *$ \\
\hline
\end{tabular}

Time: the day of flooding; $*$ and $* *$ were significantly correlated at 0.05 and 0.01 levels, respectively

Changes in the dominant soil culturable microorganisms by straw addition combined with flooding

A total of 298 strains of bacteria and 376 strains of fungi were screened and identified. The bacteria belong to 4 phyla 7 classes, 12 orders, 22 families, 22 genera, and the fungi belong to 2 phyla, 3 classes, 7 orders, 15 families and 17 genera. After flooding 120 days, the total number of bacteria and fungi were 216 and 245 respectively, and the total number of bacteria and fungi decreased by 82 and 131 respectively, compared to unflood (Tables A2 and A3).

RSD-FS treatment had obvious changes of soil culturable microorganisms (Fig. 4). For bacteria genera, Bacillus and Brevibacterium could not be cultivated after flooding 30 days; lysine Bacillus finally dying out after flooding 90 days; The genus pseudoxanthomonas decreased at first and then increased after flooding 60-120 days; The Agrobacterium increased first and then decreased, and decreased slowly after 
60 days; The Leckercia showed a trend of decreasing first and then increasing, and the increase was gradually slowed down from flooding 60 to 120 day; Enterobacter had a tendency of increasing first and then decreasing, and the decreasing range became larger gradually after 60 days of flooding. The Aeromonas increased first and then decreased, and decreased gradually after 60 days of flooding (Fig. 4a).
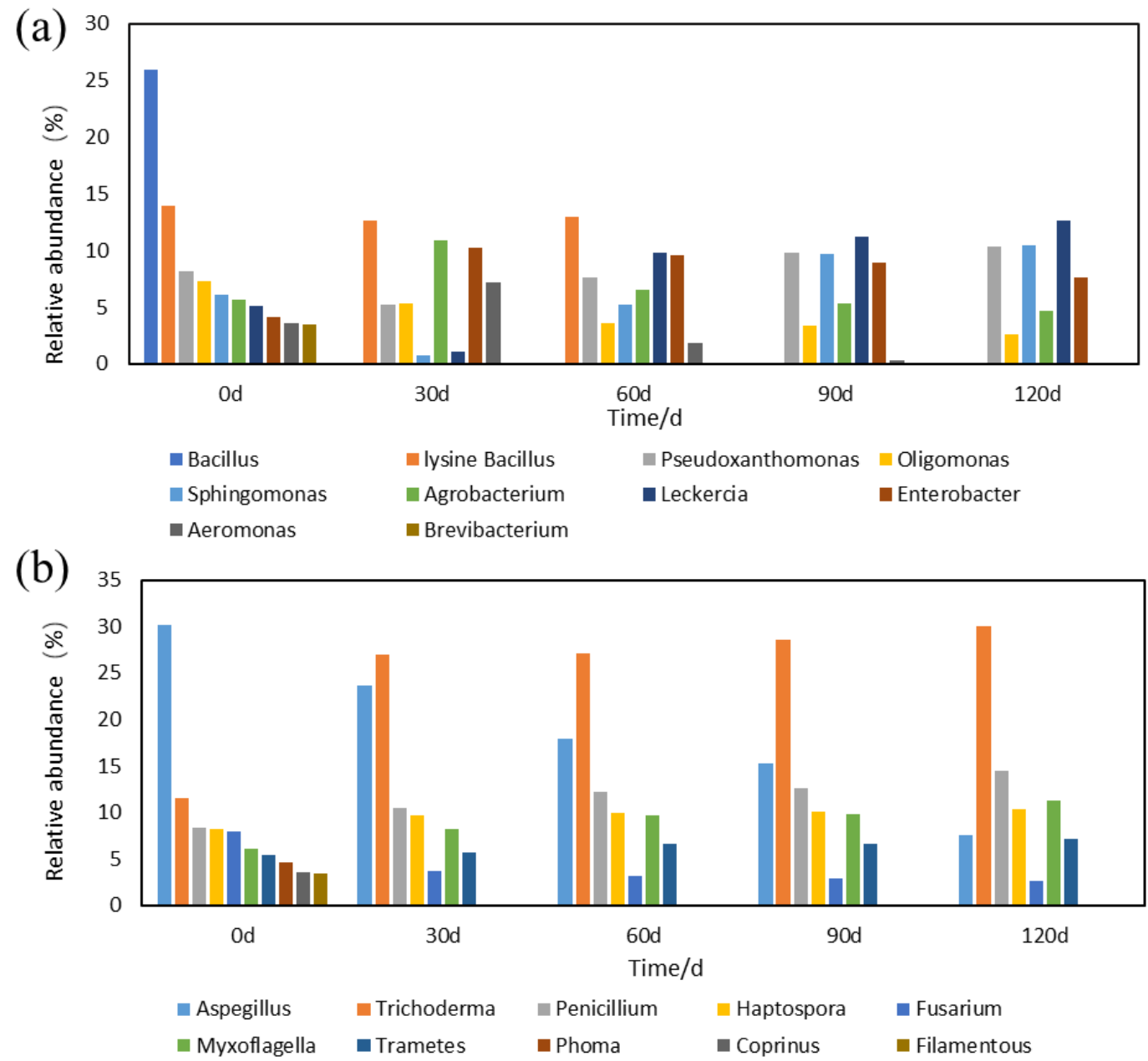

Figure 4. TOP10 cultivable bacterial (a) and (b) fungal genera dynamic changes in flooded soil with straw addition

The dominant fungi of Phoma, Coprinus and Filamentous could not be cultured after flooding 30 days; The relative abundance of Aspegillus before flooding was the highest, which decreased by $7.61 \%$ at 120 days after flooding; The relative abundance of Trichoderma showed a continuous increasing trend, and the maximum increase was $15.45 \%$ at 30 days after flooding; The relative abundance of Penicillium showed an increasing trend, and the maximum increase was $2.2 \%$ after 30 days of flooding. The Fusarium abundance showed a decreasing trend, the biggest decrease was $0.5 \%$ after 60 days of flooding. The Myxoflagella abundance showed an increasing trend, and the maximum increase was $2.08 \%$ after 30 days of flooding; The Trametes abundance showed an increasing trend, and the maximum increase was $0.88 \%$ after 60 days of flooding (Fig. 4b). 


\section{Relationship between Fusarium oxysporum and dominant microorganisms and soil properties after RSD-FS treatment}

The number of soils $F$. oxysporum was negatively correlated with soil $\mathrm{pH}$ and ammonium ( $\mathrm{p}<0.01)$, but positively correlated with soil Eh and nitrate. In addition, there was a significant correlation between the number of $F$. oxysporum and the number of the dominant culturable bacteria and fungi in the soil. Such as, the dominant bacterial genera including of Bacillus, stenotrophomonas, aeromonas, brevibacterium, and the dominant genera Aspergillus, Fusarium, Phoma, Coprinus and Filamentous, there was a significant positive correlation between the number of cultural $F$. oxysporum $(\mathrm{p}<0.01)$, this indicated that these microflora might be the potential harmful microorganisms; However, there was a significant negative correlation between the number of Enterobacter, Trichoderma, Penicillium, Myxosporea, Trametes and the number of $F$. oxysporum ( $<<0.01)$, and these genera groups might be potential beneficial microorganisms. Besides Enterobacter, flooding time was significantly correlated with other dominant bacteria and fungi $(\mathrm{p}<0.01)$, while soil $\mathrm{pH}, \mathrm{Eh}$, the contents of ammonium and nitrate were almost correlated with the potential beneficial and harmful microorganisms $(\mathrm{p}<0.01)($ Table 1$)$.

\section{Discussion}

Our results provided evidence that straw addition combined with flooding could reduce the incidence of banana fusarium wilt effectively, and change the biological and abiotic characteristics of the susceptible soil. And this pattern is consistent with previously reported that the Reductive Soil Disinfestation (RED) method in preventing soilborne diseases (Liu et al., 2019; Huang et al., 2015)

It is well known that there is a direct positive correlation between the number of soil pathogen F. oxysporum and the severity of the disease (Shen et al., 2014, 2019). With or without Straw, flooding for 30 days significantly reduced the number of $F$. oxysporum, and the trend remained the same after 30 days until 120 days (Fig. 1). This suggests that flooding measures played a relatively more important role, and could be interpreted as providing unfavorable conditions for the growth of $F$. oxysporum (Huang et al., 2015). Straw returning as potential fertility of soil, can provide carbon and nitrogen sources for soil microorganisms in the process of flooding (Dong et al., 2018). However, it was found that the shredded straw could form larger pore structure in a waterlogged environment, which provided living space for fungal chlamydospores (Jang et al., 2018). It suggested that straw addition might be beneficial to the survival of pathogens. Previous studies have shown that an increase in bacteria or fungi diversity contributes to a decrease in F. oxysporum (Wang et al., 2015). This could be explained by an increase in bacterial diversity that reinforces the general inhibition, expands the array of nutrient acquisition strategies, and increases the likelihood of a strong competitor to the $F$. oxysporum. Although the flooding measures in this study reduced the number and diversity of culturable bacteria and fungi in the soil, the reduction in the number of $F$. oxysporum was even greater, the results showed that the possible negative effects of flooding and Straw addition could be offset by the effect of disease control. It should be noted that fallow is ineffective because the $F$. oxysporum usually persists in the soil for more than 20 years (Stotzky and Torrence Martin, 1963). Although fallow can also reduce the number and incidence of $F$. oxysporum but the effect of fallow is far less than that of flooding. 
The importance of microbial populations for disease suppression has been demonstrated by the loss of support in soil sterilization (Noble and Coventry, 2005). Microbes which occupy most part of farmland soil is more likely to participate in environmental activities, and to some extent affect the distribution of soil microbes, but the mechanism is still unknown. Before the treatment of fallow, the dominant bacterial genera were Bacillus, Pseudoxanthomonas, Sphingomonas and Agrobacterium. This result was consistent with that of (Yang et al., 2020). At the same time, Penicillium and Aspergillus are the most dominant species in the fungal community, and Fusarium was abundant, which are basically consistent with the previous results (Lee and Kim, 2020). Our results showed that the structure of soil microbial community under straw addition combined with flooding treatment changed significantly, Leckerciaas replaced Bacillus to become the new dominant bacteria genus; Trichoderma replaced Aspergillus to become the new dominant fungal genus. The largely application of Trichoderma strains with biocontrol and plant growth-promoting capacities that highly suppressed the pathogen $F$. oxysporum (Bunbury-Blanchette and Walker, 2019; Martínez-Medina et al., 2014; Xiong et al., 2017). For example, Trichoderma strains can take advantage of limited living space to grow and reproduce quickly and capture water and nutrients (López-Mondéjar and Pascual, 2011), also can secrete a few bacteriostatic chemical substances to wait (Saravanakumar et al., 2016). Lee and Kim (2020) pointed out that the Leckercia genus has a strong survival ability in harsh environment, and was insensitive to environmental changes, so it is more suitable than aerobic microorganisms in the application of the promotion. It is suggested that the inhibition of straw addition combined with flooding may be explained as, Trichoderma spp. and Leckercia spp. may be able to compete for space and nutrients in the presence of limited resources, these two dominant groups will play a great role in the biocontrol of $F$. oxysporum in the future.

The modification of soil physical and chemical characteristics plays an important role in control of banana Fusarium wilt (Hong et al.,2020). Many previous studies reported that the severity of banana Fusarium wilt was negatively correlated with soil $\mathrm{pH}$ (Shen et al., 2014, 2019), and the which was consistent with the results of this study and other result that significantly increased the $\mathrm{pH}$ level by reductive soil disinfestation (Huang et al., 2015; Liu et al., 2016). Soil pH changes with the input of material (carbon source, nitrogen source, etc.), and affects other abiotic and biological properties of the soil (Brady and Weil, 2004). For example, soil pH directly affects soil nutrient availability, especially for oxidation and reduction sensitive micronutrient (Dhungana and Crumbliss, 2005); $\mathrm{pH}$ is strongly positively correlated with bacterial diversity and abundance. Bacterial diversity can double between $\mathrm{pH} 4$ and 8 (Rousk et al., 2010) 38. While many studies have shown the effect of $\mathrm{pH}$ on $F$. oxysporum, our understanding of this relationship is still incomplete. For each combination of soil conditions and management systems, it is assumed that there is an optimal $\mathrm{pH}$ for plant growth and disease suppression. The relationship between $\mathrm{pH}$ and inhibition needs to be studied in the field to better understand these complex interactions. Interestingly, we found that no matter whether straw was added or not, the nitrate content decreased with the increase of flooding time, while the ammonium decreased. This may be related to the enhancement of nitrate uptake in banana by flooding or the inhibition of nitrification in flooded and anoxic environment. In addition, the correlation analysis further indicated that soil $\mathrm{pH}, \mathrm{Eh}$, ammonium and nitrate content might be the key physical and chemical factors impact the potential beneficial and harmful microbe associated with $F$. oxysporum (Table 1). 


\section{Conclusions}

The incidence of banana fusarium wilt by straw-adding combined with flooding was significantly lower than that by single flooding and other non-flooding treatments (continuous cropping and fallow). Flooding and Straw addition method significantly reduced the amount of the pathogen $F$. oxysporum, culturable bacteria and fungi in the soil. It also increased the soil $\mathrm{pH}$ and reduced $\mathrm{Eh}$ and nitrate nitrogen levels after strawadding combined flooding. A remarkable shift has happened in microbial community by the straw-adding combined flooding. When the flooding was doner, the key genus Leckercia took the place of the genus Bacillus, and the key genus Trichoderma took the place of the genus Aspergillus. Further studies (e.g., secreted antagonists) on the interactions of these two dominant species with pathogens will be needed. To sum up, the measures of flooding combined with straw addition can just offset the shortage of a single measure, which makes the banana fusarium wilt prevention and control achieve optimistic results.

Acknowledgements. This research was financially supported by National Natural Science Foundation of China (31672239), National Key Basic Research Program of China (2015CB150503).

\section{REFERENCES}

[1] Alkhaibari, A. M., Maffeis, T., Bull, J. C., Butt, T. M. (2018): Combined use of the entomopathogenic fungus, Metarhizium brunneum, and the mosquito predator, Toxorhynchites brevipalpis, for control of mosquito larvae: is this a risky biocontrol strategy? - Journal of Invertebrate Pathology 153: 38-50.

[2] Altschul, S. F., Madden, T. L., Schäffer, A. A., Zhang, J., Zhang, Z., Miller, W., Lipman, D. J. (1997): Gapped BLAST and PSI-BLAST: a new generation of protein database search programs. - Nucleic Acids Research 25(17): 3389-3402.

[3] Ben-David, A., Davidson, C. E. (2014): Estimation method for serial dilution experiments. - Journal of Microbiological Methods 107: 214-221.

[4] Brady, N. C., Weil, R. R. (2004): Elements of the Nature and Properties of Soils. - Journal of Microbiological Methods 278.

[5] Bunbury-Blanchette, A. L., Walker, A. K. (2019): Trichoderma species show biocontrol potential in dual culture and greenhouse bioassays against Fusarium basal rot of onion. Biological Control 130: 127-135.

[6] Dhungana, S., Crumbliss, A. L. (2005): Coordination chemistry and redox processes in siderophore-mediated iron transport. - Geomicrobiology Journal 22(3-4): 87-98.

[7] Dong, L., Linghu, W., Zhao, D., Mou, Y., Hu, B., Asiri, Abdullah, M., Alamry, K. A., Xu, D. (2018): Performance of biochar derived from rice straw for removal of Ni (II) in batch experiments. - Water Science and Technology 77: 824-834.

[8] Food and Agriculture Organization of the United Nations (FAOSTAT) (2017): Data of crop production (2016-12-08) [2017-04-02]. - http://www.fao.org/faostat/en/\#data/QC.

[9] Franzluebbers, A. J. (2002): Soil organic matter stratification ratio as an indicator of soil quality. - Soil and Tillage Research 66(2): 95-106.

[10] Hong, S., Jv, H., Lu, M., Wang, B., Zhao, Y., Ruan, Y. (2020): Significant decline in banana Fusarium wilt disease is associated with soil microbiome reconstruction under chilli pepper-banana rotation. - European Journal of Soil Biology 97: 103154.

[11] Huang, X., Liu, L., Wen, T., Zhu, R., Zhang, J., Cai, Z. (2015): Illumina MiSeq investigations on the changes of microbial community in the Fusarium oxysporum $\mathrm{f}$. sp. 
cubense infected soil during and after reductive soil disinfestation. - Microbiological Research 181: 33-42.

[12] Hwang, S. C., Ko, W. H. (2004): Cavendish banana cultivars resistant to fusarium wilt acquired through somaclonal variation in Taiwan. - Plant Disease 88(6): 580-588.

[13] Jang, J., Mirana, W., Divine, S. D., Nawaz, M., Shahzad, A., Woo, S. H., Lee, D. S. (2018): Rice straw-based biochar beads for the removal of radioactive strontium from aqueous solution. - Science of the Total Environment 615: 698-707.

[14] Komada, H. (1975): Development of a selective medium for quantitative isolation of Fusarium oxysporum from natural soil. - Review of Plant Protection Research 8: 114-124.

[15] Larkin, R. P., Griffin, T. S. (2007): Control of soilborne potato diseases using Brassica green manures. - Crop Protection 6: 1067-1077.

[16] Lee, H., Ahmad, R., Kim, J. (2020): Alginate to simulate biofouling in submerged fluidized ceramic membrane reactor: effect of solution $\mathrm{pH}$ and ionic strength. - Bioresource Technology 302: 122813.

[17] Liu, L., Kong, J., Cui, H., Zhang, J., Wang, F., Cai, Z., Huang, X. (2016): Relationships of decomposability and $\mathrm{C} / \mathrm{N}$ ratio in different types of organic matter with suppression of Fusarium oxysporum and microbial communities during reductive soil disinfestation. Biological Control 101: 103-113.

[18] Liu, L., Huang, X., Zhao, J., Zhang, J., Caia, Z. (2019): Characterizing the key agents in a disease-suppressed soil managed by reductive soil disinfestation. - Applied and Environmental Microbiology 85(7): e02992-18.

[19] López-Mondéjar, R., Ros, M., Pascual, J. A. (2011): Mycoparasitism-related genes expression of Trichoderma harzianum isolates to evaluate their efficacy as biological control agent. - Biological Control 56(1): 59-66.

[20] Macwilliams, M. P., Liao, M.-K. (2006): Luria Broth (LB) and Luria Agar (LA) Media and Their Uses Protocol. - American Society for Microbiology, Washington, DC.

[21] Martin, G. R. (1981): Isolation of a pluripotent cell line from early mouse embryos cultured in medium conditioned by teratocarcinoma stem cells. - Proceedings of the National Academy of Sciences of the United States of America 78(12): 7634-7638.

[22] Martínez-Medina, A., Del Mar Alguacil, M., Pascual, J. A., Van Wees, S. C. M. (2014): Phytohormone profiles induced by trichoderma isolates correspond with their biocontrol and plant growth-promoting activity on melon plants. - Journal of Chemical Ecology 40(7): 804-15.

[23] Messiha, N. A. S., Van Diepeningen, A. D., Wenneker, M., Van Beuningen, A. R., Janse, J. D., Coenen, T. G. C., Termorshuizen, A. J., Van Bruggen, A. H. C., Blok, W. J. (2007): Biological Soil Disinfestation (BSD), a new control method for potato brown rot, caused by Ralstonia solanacearum race 3 biovar 2. - European Journal of Plant Pathology 177(4): 403-415.

[24] Mostert, D., Molina, A. B., Daniells, J., Fourie, G., Hermanto, C., Chao, C. P., Fabregar, E., Sinohin, V. G., Masdek, N., Thangavelu, R., Li, C., Yi, G., Mostert, L., Viljoen, A. (2017): The distribution and host range of the banana Fusarium wilt fungus, Fusarium oxysporum $\mathrm{f}$. sp. cubense, in Asia. - Plos one 12(7): e0181630.

[25] Noble, R., Coventry, E. (2005): Suppression of soil-borne plant diseases with composts: a review. - Biocontrol Science and Technology 15(1): 3-20.

[26] Ploetz, R. C. (2015): Management of Fusarium wilt of banana: a review with special reference to tropical race 4. - Crop Protection 73: 7-15.

[27] Rasool, R., Kukal, S. S., Hira, G. S. (2008): Soil organic carbon and physical properties as affected by long-term application of FYM and inorganic fertilizers in maize-wheat system. - Soil and Tillage Research 101: 31-36.

[28] Rousk, J., Bååth, E., Brookes, P. C., Lauber, C. L., Lozupone, C., Caporaso, J. G., Knight, R., Fierer, N. (2010): Soil bacterial and fungal communities across a pH gradient in an arable soil. - ISME Journal 4: 1340-1351. 
[29] Saravanakumar, K., Yu, C., Dou, K., Wang, M., Li, Y., Chen, J. (2016): Synergistic effect of Trichoderma-derived antifungal metabolites and cell wall degrading enzymes on enhanced biocontrol of Fusarium oxysporum f. sp. cucumerinum. - Biological Control 94: $37-46$.

[30] Schoch, C. L. et al. (2012): Nuclear ribosomal internal transcribed spacer (ITS) region as a universal DNA barcode marker for Fungi. - Proceedings of the National Academy of Sciences of the United States of America 109: 6241-6246.

[31] Shen, Z., Wang, D., Ruan, Y., Xue, C., Zhang, J., Li, R., Shen, Q. (2014): Deep 16S rRNA pyrosequencing reveals a bacterial community associated with banana Fusarium wilt disease suppression induced by bio-organic fertilizer application. - PLoS One 9(5): 1-10.

[32] Shen, Z., Xue, C., Penton, C. R., Thomashow, L. S., Zhang, N., Wang, B., Ruan, Y., Li, R., Shen, Q. (2019): Suppression of banana Panama disease induced by soil microbiome reconstruction through an integrated agricultural strategy. - Soil Biology and Biochemistry 128: 164-174.

[33] Stotzky, G., Torrence Martin, R. (1963): Soil mineralogy in relation to the spread of fusarium wilt of banana in central America. - Plant and Soil 18(3): 317-337.

[34] Surekha, K., Padma Kumari, A. P., Narayana Reddy, M., Satyanarayana, K., Sta Cruz, P. C. (2003): Crop residue management to sustain soil fertility and irrigated rice yields. Nutrient Cycling in Agroecosystems 67(2): 145-154.

[35] Wang, B., Li, R., Ruan, Y., Ou, Ya., Zhao, Y., Shen, Q. (2015): Pineapple-banana rotation reduced the amount of Fusarium oxysporum more than maize-banana rotation mainly through modulating fungal communities. - Soil Biology and Biochemistry 86: 77-86.

[36] Wen, T., Huang, X., Zhang, J., Cai, Z. (2016): Effects of biological soil disinfestation and water regime on suppressing Artemisia selengensis root rot pathogens. - Journal of Soils and Sediments 16(1): 215-225.

[37] Xiong, W., Guo, S., Jousset, A., Zhao, Q., Wu, H., Li, R., Kowalchuk, G. A., Shen, Qi. (2017): Bio-fertilizer application induces soil suppressiveness against Fusarium wilt disease by reshaping the soil microbiome. - Soil Biology and Biochemistry 114: 238-247.

[38] Yang, F., Huai, W. X., Zeng, Y. H. (2020): New dynamic two-layer model for predicting depth-averaged velocity in open channel flows with rigid submerged canopies of different densities. - Advances in Water Resources 138: 103553.

[39] Yu, J., Zhou, X. F., Yang, S. J., Liu, W. H., Hu, X. F. (2013): Design and application of specific 16S rDNA-targeted primers for assessing endophytic diversity in Dendrobium officinale using nested PCR-DGGE. - Applied Microbiology and Biotechnology 97(22): 9825-9836.

\section{APPENDIX}

Table A1. Analysis of variance of investigated parameters

\begin{tabular}{c|c|c|c}
\hline & Treatment & Time & Treatment $\times$ Time \\
\hline $\mathrm{pH}$ & $3.58^{*}$ & 1.55 & 1.17 \\
$\mathrm{Eh}$ & $30.86^{* *}$ & $14.75^{* *}$ & $5.07^{* *}$ \\
$\mathrm{NH}_{4}{ }^{+}-\mathrm{N}$ & $69.75^{* *}$ & $30.31^{* *}$ & $2.45^{*}$ \\
$\mathrm{NO}_{3}-\mathrm{N}$ & $76874.4^{* *}$ & $51949.2^{* *}$ & $3394.23^{* *}$ \\
F. oxysporum CFU & $25745.2^{* *}$ & $29635.3^{* *}$ & $3238.1^{* *}$ \\
Bacteria CFU & $5471.78^{* *}$ & $1509.1^{* *}$ & $351.49^{* *}$ \\
Fungus CFU & $1585.98^{* *}$ & $259.5^{* *}$ & $244.72^{* *}$ \\
\hline
\end{tabular}

$*$ and $* *$ were significantly different at 0.05 and 0.01 levels, respectively 
Table A2. Changes of bacterial population during flooding cycle

\begin{tabular}{c|c|c|c|c|c|c}
\hline Time (d) & Total number & Phyla & Classes & Orders & Families & Genera \\
\hline 0 & 298 & 4 & 7 & 12 & 15 & 22 \\
30 & 223 & 2 & 4 & 6 & 10 & 12 \\
60 & 218 & 2 & 4 & 6 & 10 & 11 \\
90 & 201 & 2 & 4 & 6 & 10 & 11 \\
120 & 216 & 2 & 4 & 6 & 10 & 10 \\
\hline
\end{tabular}

Table A3. changes of fungal population during flooding cycle

\begin{tabular}{c|c|c|c|c|c|c}
\hline Time $(\mathbf{d})$ & Total number & Phyla & Classes & Orders & Families & Genera \\
\hline 0 & 376 & 2 & 3 & 7 & 15 & 17 \\
30 & 266 & 1 & 2 & 4 & 7 & 9 \\
60 & 215 & 1 & 2 & 4 & 7 & 9 \\
90 & 265 & 1 & 2 & 4 & 7 & 9 \\
120 & 245 & 1 & 2 & 4 & 7 & 9 \\
\hline
\end{tabular}

